\title{
ANÁLISE QUALITATIVA DAS PREPARAÇÕES DO CARDÁPIO MENSAL DE UM HOSPITAL DO MUNICÍPIO DE SANTA MARIA ${ }^{1}$
}

\author{
QUALITATIVE ANALYSIS OF THE MONTHLY MENU OF \\ A HOSPITAL IN THE MUNICIPALITY OF SANTA MARIA
}

\author{
Josiane Erbice Bianchini $^{2}$ e Cristiana Basso ${ }^{3}$
}

\section{RESUMO}

Este trabalho teve como objetivo avaliar qualitativamente as preparações do cardápio mensal de um hospital privado do município de Santa Maria. A avaliação do cardápio realizou-se durante o mês de setembro de 2019 através de análises diárias quanto às técnicas de cocção; cor das saladas e combinação de cores das preparações. Além da análise semanal desses itens, avaliaram-se repetições de preparações, presença de folhosos, frutas, carnes gordurosas e o teor de enxofre dos alimentos. Ademais, analisou-se o percentual de ocorrência mensal dos itens citados acima. Os resultados apontaram percentual de ocorrência para folhosos e cores iguais (74\%), ricos em enxofre (11\%), doces $(100 \%)$, frituras e frituras + doces $(21 \%)$. Para a ocorrência de frutas e carnes gordurosas, o percentual foi nulo. Diante disso, observou-se necessidade de melhoria do planejamento do cardápio com o objetivo de prevenir o aparecimento de monotonias de cores e preparações. É importante ressaltar a importância da qualidade nutricional das preparações visto que os pacientes realizam as principais refeições do dia no âmbito hospitalar e isso poderá auxiliar não só na recuperação da saúde dos mesmos, mas na manutenção da saúde dos funcionários.

Palavras-chave: Cardápio, Método AQPC, Serviços de Alimentação.

\section{ABSTRACT}

This work aimed to qualitatively evaluate the preparations of the monthly menu of a private hospital in the municipality of Santa Maria. The evaluation of the menu was carried out during the month of September 2019 through daily analysis of cooking techniques; color of salads and color combination of preparations. In addition to weekly analysis of these items, repetitions of preparations, presence of leafy vegetables, fruits, fatty meats and the sulfur content of foods were evaluated. In addition, the percentage of monthly occurrence of the items mentioned above was analyzed. The results showed a percentage of occurrence for leafy and equal colors (74\%), rich in sulfur (11\%), sweets (100\%), fried and fried foods + sweets $(21 \%)$. For the occurrence of fruits and fatty meats, the percentage was zero. Therefore, there was a need to improve the menu planning in order to prevent the appearance of monotonies of colors and preparations. It is important to emphasize the importance of the nutritional quality of the preparations since patients have the main meals of the day in the hospital and this can assist not only in recovering their health, but in maintaining the health of employees.

Keywords: Menu, AQPC method, Food Services.

\footnotetext{
${ }^{1}$ Trabalho desenvolvido no estágio em serviço de alimentação e nutrição - Nutrição/UFN.

${ }^{2}$ Nutricionista, pela Universidade Franciscana - UFN. josianeerbicebianchini@gmail.com

${ }^{3}$ Nutricionista, Professora do Curso de Nutrição - UFN. cristiana@ufn.edu.br
} 


\section{INTRODUÇÃO}

A alimentação saudável e de qualidade é condição fundamental para a promoção da saúde dos indivíduos. As Unidades de Alimentação e Nutrição (UAN) compõem um conjunto de áreas que pretendem operacionalizar o provimento nutricional de coletividades. Destina-se ao fornecimento de refeições balanceadas dentro dos padrões dietéticos e higiênicos, visando atender às necessidades nutricionais de seus clientes, ajustando-se aos limites financeiros da instituição (ABREU; SPINELLI; PINTO, 2013).

O cardápio é uma ferramenta inicial no processo produtivo e serve como instrumento gerencial para a administração do serviço de alimentação. Em UAN, o planejamento dos cardápios deve ser realizado por especialistas com a finalidade de programar refeições que atendam a pré-requisitos, como hábitos alimentares e características nutricionais dos comensais, qualidade higiênico-sanitária, adequação ao mercado de abastecimento e à capacidade de produção (ABREU; SPINELLI; PINTO, 2013; RAMOS et al., 2013).

Também deve ser utilizado para promover a educação alimentar e nutricional, corresponder ou exceder as expectativas dos clientes, desenvolver hábitos alimentares saudáveis e propiciar o retorno de investimentos (BOTELHO, 2018; VEIROS; PROENÇA, 2003). Segundo Ribeiro e Monteiro (2015), o planejamento de bons cardápios deve ser tratado com prioridade e seriedade, exigindo certa habilidade do profissional nutricionista, o qual tem como uma de suas atribuições elaborar os cardápios de acordo com o diagnóstico nutricional da clientela, respeitando os hábitos alimentares regionais, culturais e étnicos (BRASIL, 2018).

É indispensável que os profissionais das UAN façam avaliações qualitativas e quantitativas periódicas dos cardápios para que estejam adequados aos comensais, evitando assim desequilíbrios e monotonia alimentícia. Caso se constate inadequações, essas devem ser corrigidas (SANTOS, 2016).

Frente ao método de avaliação qualitativa das preparações do cardápio (AQPC), é possível detectar falhas e definir soluções a serem implementadas para a sua revisão e adequação, de forma a considerar a manutenção da saúde dos indivíduos e a satisfatória oferta de nutrientes (VIEIRA; SPINELLI, 2018).

Nesse contexto, este trabalho tem por objetivo avaliar qualitativamente as preparações do cardápio mensal de um hospital do município de Santa Maria, RS.

\section{MATERIAIS E MÉTODOS}

Trata-se de um estudo do tipo quantitativo realizado no estágio curricular em Serviços de Alimentação da Universidade Franciscana, com consentimento da nutricionista do local. Realizou-se uma análise qualitativa do cardápio mensal das preparações do almoço ofertado para os pacientes em 
dieta livre e funcionários de um hospital privado, localizado no município de Santa Maria (RS-Brasil), durante o mês de setembro do ano de 2019, através do método AQPC. Foram incluídas as preparações do almoço de segunda a sexta-feira e excluídas as preparações do jantar, lanches e feriados devido às alterações alimentares realizadas.

Sendo assim, analisou-se o cardápio do almoço diariamente conforme metodologia adaptada e descrita por Veiros e Proença (2003). Resumidamente, a aplicação do método AQPC considerou as seguintes etapas:

1. As preparações foram avaliadas diariamente, sob os seguintes critérios: técnicas de cocção; cor das saladas e combinação de cores de todas as preparações diárias;

2. Semanalmente, foram realizados os agrupamentos dos dados diários, avaliando o número de preparações com alimentos ricos em enxofre; aparecimento de folhosos, de conservas nas saladas e de frutas nas sobremesas; presença de doces, ou seja, preparações elaboradas como sobremesa; frequência de fritura e frituras acompanhadas com doces; dias com repetições de preparações e com repetições no jogo de cor, dias com carne gordurosa, e opções de carne frita.

3. A avaliação mensal constou no agrupamento dos dados semanais posteriormente tabulados em percentuais de ocorrência de frutas, folhosos, cores iguais, ricos em enxofre, doces, frituras, carne gordurosa, frituras + doce.

Os resultados foram analisados e tabulados para elaboração das tabelas no software Microsoft WordC, versão 2010.

\section{RESULTADOS E DISCUSSÃO}

São servidas em média 49 refeições por dia entre funcionários e pacientes. O cardápio é constituído por: 2 acompanhamentos: 1 tipo de arroz, feijão ou lentilha;

1 Prato Principal: Carne de panela, filé de frango, bife acebolado (cortes magros) iscas de frango a milanesa, filé de frango grelhado, sobrecoxa assada, almondegas, pastel de frios, carne suína assada e peixe frito. Essas são algumas das preparações mais frequentes.

1 Guarnição: Legumes refogados, mandioca ou batata doce cozida, moranga caramelada, batata frita, batata palha, purês ou polenta. Eventualmente, são servidas preparações como lasanha à bolonhesa, risotos, suflês ou panquecas. Saladas (2 ou 3 variedades): Alface, tomate, couve-flor, brócolis, cenoura crua ou cozida, beterraba crua ou cozida. Essas são as opções mais usuais. Bebida: Suco artificial com variação de sabores. Sobremesa: Gelatina com variação de sabores.

A tabela 1 apresenta a compilação dos dados resultantes da avaliação semanal de quatro semanas do Serviço de Nutrição e Dietética do hospital estudado. A tabela 2 apresenta o agrupamento mensal dos dados. 
Tabela 1 - Análise semanal do cardápio de um Hospital de Santa Maria-RS.

\begin{tabular}{|c|c|c|c|c|}
\hline \multicolumn{5}{|c|}{ AVALIAÇÃO SEMANAL } \\
\hline & Sem. 1 & Sem. 2 & Sem. 3 & Sem. 4 \\
\hline Dias úteis & 5 & 5 & 4 & 5 \\
\hline Dias com fritura & 0 & 1 & 2 & 1 \\
\hline Dias com repetições de preparações & 4 & 4 & 3 & 2 \\
\hline Dias com frutas de sobremesa & 0 & 0 & 0 & 0 \\
\hline Dias com doces de sobremesa & 5 & 5 & 5 & 5 \\
\hline Dias com repetições no jogo de cor & 4 & 3 & 3 & 4 \\
\hline Dias com alimentos ricos em enxofre & 0 & 2 & 0 & 0 \\
\hline Dias com salada de folhosos & 4 & 3 & 4 & 3 \\
\hline Dias com salada de conserva & 0 & 0 & 0 & 0 \\
\hline Dias com fritura acompanhada de doce & 0 & 1 & 2 & 1 \\
\hline Dias com carne gordurosa & 0 & 0 & 0 & 0 \\
\hline Dias com opção de carne frita & 0 & 1 & 1 & 1 \\
\hline
\end{tabular}

Tabela 2 - Agrupamento dos dados mensais do cardápio de um Hospital de Santa Maria-RS.

\begin{tabular}{|ccc}
\hline & AVALIAÇÃO MENSAL & \\
\hline Mês avaliado & Dias de cardápio: & \% de ocorrência \\
\hline Frutas & 0 & $0 \%$ \\
\hline Folhosos & 14 & $74 \%$ \\
\hline Cores iguais & 14 & $74 \%$ \\
\hline Rico em enxofre & 2 & $11 \%$ \\
\hline Doces & 19 & $100 \%$ \\
\hline Frituras & 4 & $21 \%$ \\
\hline Carnes gordurosas & 0 & $0 \%$ \\
\hline Frituras + Doces & 4 & $21 \%$ \\
\hline
\end{tabular}

Avaliaram-se 19 dias úteis do cardápio. Através da análise nutricional qualitativa das preparações alimentares observou-se a inexistência da oferta de frutas e a oferta de doces como sobremesa presente em todos os dias estudados. Somente a gelatina foi a preparação utilizada como sobremesa, apenas com variação de sabores e cores.

A maior disponibilidade de doces ao invés da oferta de frutas corresponde a uma falha na elaboração dos cardápios a ser destacada. O Ministério da Saúde (BRASIL, 2014) afirma que os doces não são alimentos nutritivos e contêm elevado teor de açúcar, contribuindo para o aumento da prevalência de sobrepeso e obesidade. Em oposição aos doces, as frutas devem estar presentes diariamente na alimentação da população por apresentarem baixa densidade energética, alto teor de fibras, componentes antioxidantes, além de serem fontes de micronutrientes (FRANCO et al., 2013).

A oferta de folhosos teve um alto percentual de ocorrência (74\%), corroborando com o estudo de Vieira e Spinelli (2018). Nesse estudo, analisaram a qualidade de cardápios de uma UAN hospitalar onde apresentou-se a oferta de folhosos na maioria dos dias (100\%). Apesar da oferta de folhosos ter apresentado alto percentual, a maior oferta reduziu-se à alface. 
Observou-se monotonia de cores em 74\% dos dias. Semelhante ao estudo de Ramos, et al. (2013), em que o cardápio de uma Unidade de Alimentação e Nutrição também foi avaliado pelo método AQPC, observou-se que 69\% dos dias apresentaram preparações com semelhança de cores. Segundo Viera e Spinelli (2018), para evitar monotonia de cores, deve-se planejar adequadamente a inclusão de frutas e hortaliças na rotina. Esses alimentos possuem uma variedade de cores, proporciona agradável aspecto visual das preparações e, quanto mais colorida, maior a multiplicidade de nutrientes, como fibras, vitaminas e minerais.

Também avaliou-se a oferta de alimentos ricos em enxofre. O seu percentual resultou em 11\% dos dias, e a preparação concentrou com maior frequência a salada mista de brócolis e couve-flor. Verificou-se quando havia duas ou mais preparações com um dos seguintes itens: acelga, aipo, batata-doce, brócolis, couve-de-bruxelas, couve-flor, ervilha, lentilha, nabo, ovo, rabanete, repolho, alho e cebola, (PROENÇA, 2005), somando a presença do feijão (VEIROS; PROENÇA, 2003).

Segundo Veiros e Proença (2003) além de carne e feijão, as saladas, dependendo do tipo de hortaliça servida, colaboram para o aumento do teor de enxofre da refeição. No feijão, o desconforto é explicado pela presença de dois oligossacarídeos não digestivos, como a estaquinose e rafinose, não quebrados pelas enzimas humanas, e por ser rico em aminoácidos sulfurados aumentam a sensação de desconforto gástrico, pela produção de gases após a refeição.

Notou-se a presença de frituras em $21 \%$ dos dias, as preparações mais frequentes foram filé de peixe, ovo frito, iscas de frango e pastel de frios. Segundo Prado, Nicoletti e Faria (2014), o consumo excessivo de gordura saturada e colesterol pode levar à obesidade, dislipidemias, doenças ateroscleróticas e doenças relacionadas, como cânceres e doenças cardiovasculares. Além disso, as temperaturas elevadas observadas durante o processo de fritura levam à oxidação do óleo, fazendo com que o mesmo agregue compostos tóxicos e prejudiciais à saúde (SBC, 2013).

O aparecimento de carnes gordurosas foi inexistente em razão dos cortes utilizados terem sido filé de peito de frango, sobrecoxas, carne suína, lagarto ou patinho bovino sempre utilizando as técnicas de cocção assada ou grelhadas. Esses dados corroboram com o estudo de Ygnatios e colaboradores (2017), onde realizou-se uma avaliação qualitativa das preparações do cardápio de uma escola privada. Os resultados de tal estudo apontaram a utilização de carnes magras para elaboração da rotina alimentar, fora a remoção de toda a gordura visível, pele do frango antes da cocção, as carnes sempre foram grelhadas, assadas, cozidas ou ensopadas, utilizando pequena quantidade de óleo.

Frituras acompanhadas por doce apareceram em $21 \%$ dos dias estudados. A preparação doce foi servida em todos os dias e consequentemente coincidiu com os dias que tinha fritura no cardápio. Segundo o Guia Alimentar para População Brasileira (2014), o consumo excessivo de calorias e a oferta desequilibrada de nutrientes como gorduras saturadas e açúcares podem favorecer o risco do aparecimento de doenças crônicas. 
De acordo com Seta e colaboradores (2010), orienta-se aos serviços de alimentação e nutrição institucionais principalmente a oferta de refeições nutricionalmente equilibradas e seguras do ponto de vista da qualidade higiênico-sanitária e, adicionalmente, que possam contribuir para a recuperação ou manutenção da saúde dos indivíduos.

Por fim, quanto às conservas, não houve oferta desses alimentos no período do estudo. Esse dado se torna positivo, considerando a elevada quantidade de sódio em sua composição. A ingestão excessiva de sal está relacionada ao desenvolvimento de doenças como a hipertensão arterial (RAMOS et al., 2013).

\section{CONCLUSÃO}

Diante dos resultados encontrados pela aplicação do método AQPC, constatou-se a necessidade de melhoria do planejamento do cardápio com o objetivo de prevenir o aparecimento de monotonias de cores e preparações. Tendo em mente a importância da qualidade nutricional, deve-se prezar principalmente pelos pacientes que realizam as principais refeições do dia no âmbito hospitalar. Uma rotina alimentar variada e balanceada poderá auxiliar na recuperação da saúde do mesmo e na manutenção da saúde dos funcionários.

\section{REFERÊNCIAS}

ABREU, E. S.; SPINELLI, M. G. N.; PINTO, A. M. S. Gestão de unidades de alimentação e nutrição: um modo de fazer. 5 ed. São Paulo: Metha, 2013.

BRASIL. Ministério Da Saúde. Secretaria de Atenção à Saúde Coordenação-Geral da Política de Alimentação e Nutrição. Guia alimentar para a população brasileira. Brasília: Ministério da Saúde, 2014.

BRASIL. Conselho Federal de Nutricionistas. Resolução CFN nº 600, de 25 de fevereiro de 2018. Dispõe sobre a definição das áreas de atuação do nutricionista e suas atribuições, indica parâmetros numéricos mínimos de referência, por área de atuação, para a efetividade dos serviços prestados à sociedade e dá outras providências [internet]. Diário Oficial da União, 2018.

BOTELHO, A.J.; Planejamento de cardápios para lactentes e pré-escolares com fichas técnicas de preparações. Rio de Janeiro: Rúbio, 2018.

FRANCO, A. S. et al. Impacto da promoção sobre consumo de frutas e hortaliças em ambiente de trabalho. Revista de Saúde Pública, v. 47, n. 1, p. 29-36, 2013. 
PRADO B.G.; NICOLETTI A.; FARIA C.S. Avaliação qualitativa das preparações de cardápio em uma Unidade de Alimentação de Cuiabá-MT. Revista UNOPAR. Científica Ciências Biológicas e da Saúde, 2014.

PROENÇA, R.P.C. et al. Qualidade nutricional e sensorial na produção de refeições. Florianópolis: Editora UFSC, 2005.

RAMOS, S. A. et al. Avaliação qualitativa do cardápio e pesquisa de satisfação em uma unidade de alimentação e nutrição. Alimentação e Nutrição, v. 24, n. 1, p. 29-35, 2013.

RIBEIRO, R. C.; MONTEIRO, M. A. O planejamento de cardápios como estratégia de êxito na gestão da produção de refeições e na promoção da saúde. Nutrição em Pauta, n. 123, p. 46-50, 2015.

SANTOS, J. S. Análise qualitativa e quantitativa do cardápio semanal de um serviço de alimentação e nutrição de um hospital particular, localizado na cidade de Salvador, Bahia. Revista da Associação Brasileira de Nutrição-RASBRAN, v. 7, n. 2, p. 100-105, 2016.

SETA, M. H. et al. Cuidado nutricional em hospitais públicos de quatro estados brasileiros: contribuições da avaliação em saúde à vigilância sanitária de serviços. Ciência \& Saúde Coletiva, v. 15, p. 3413-3422, 2010.

SBC. Sociedade Brasileira de Cardiologia. I Diretriz Sobre o Consumo de Gorduras e Saúde Cardiovascular. Arquivos Brasileiros de Cardiologia. 2013

VEIROS, M. B.; PROENÇA, R. P.C. Avaliação qualitativa das preparações do cardápio em uma unidade de alimentação e nutrição: método AQPC. Nutr Pauta, v. 11, n. 62, p. 36-42, 2003.

VIEIRA, M.C.H.; SPINELLI, M.G.N. Análise da qualidade de cardápios mensais e da satisfação dos clientes de uma unidade de alimentação e nutrição hospitalar. Revista Univap, v. 25, n. 47, p. 58-69, 2018.

YGNATIOS, N. T. M.; LIMA, N. N; DAS GRAÇAS PENA, G. Avaliação qualitativa das preparações do cardápio de uma escola privada em um município do interior de Minas Gerais. Revista da Associação Brasileira de Nutrição-RASBRAN, v. 8, n. 1, p. 82-89, 2017. 
